\title{
TanDEM-X: Mission Concept and Performance Analysis
}

\author{
Gerhard Krieger, Hauke Fiedler, Irena Hajnsek, Michael Eineder, Marian Werner, Alberto Moreira \\ Microwaves and Radar Institute \\ German Aerospace Centre (DLR) \\ 82234 Oberpfaffenhofen, Germany \\ E-Mail: Gerhard.Krieger@dlr.de
}

\begin{abstract}
This paper analyses the potential of TanDEM-X to acquire highly accurate digital elevation models (DEMs) on a global scale. For this, an appropriate mission concept will be introduced which allows for the generation of a world-wide DEM according to the emerging HRTI level 3 standard within 3 years. The achievable height accuracy will be derived from a detailed performance analysis taking into account the major system and scene parameters. Critical issues will be identified together with a derivation of essential requirements on both the system and mission level.
\end{abstract}

\section{INTRODUCTION}

TanDEM-X is a mission proposal for an innovative spaceborne radar interferometer which is currently evaluated in a phase A study by a joint DLR and EADS/Astrium team [1]. The mission concept is based on two TerraSAR-X radar satellites flying in close formation to achieve the desired interferometric baselines in a highly reconfigurable configuration [2]. Major goal of the TanDEM-X mission is the generation of a world-wide, consistent, timely, and highprecision digital elevation model (DEM) according to the emerging DTED/HRTI-3 standard (cf. Table I) as the basis for a wide range of scientific research, as well as for operational and commercial DEM production [3]. Besides the primary goal of the mission, several other secondary mission objectives based on along-track interferometry as well as new techniques with bistatic SAR have been defined which also represent an important and innovative asset of the mission.

TABLE I. DEM SPECIFICATION FOR HRTI LEVEL -3 STANDARD

\begin{tabular}{|c|c|c|}
\hline Requirement & Specification & HRTI-3 \\
\hline Relative Vertical Accuracy & $\begin{array}{l}90 \% \text { linear point-to- } \\
\text { point error }\end{array}$ & $\begin{array}{l}2 m(\text { slope }<20 \%) \\
4 m(\text { slope }>20 \%)\end{array}$ \\
\hline Absolute Vertical Accuracy & $90 \%$ linear error & $10 \mathrm{~m}$ \\
\hline Horizontal Accuracy & $90 \%$ circular error & $10 \mathrm{~m}$ \\
\hline Spatial Resolution & independent pixels & $12 \mathrm{~m}$ (1 arc sec) \\
\hline
\end{tabular}

\section{MISSION CONCEPT}

The TanDEM-X mission concept is based on an extension of the TerraSAR-X mission [4] by a second TerraSAR-X like satellite (TanDEM-X). Both satellites will fly in a close orbit formation and will be operated as a flexible single-pass SAR interferometer, where the baseline can be selected according to the specific needs of the application (cf. Figure 1). This enables the acquisition of highly accurate cross-track and along-track interferograms without the inherent accuracy limitations imposed by repeat-pass interferometry due to temporal decorrelation and atmospheric disturbances [5].

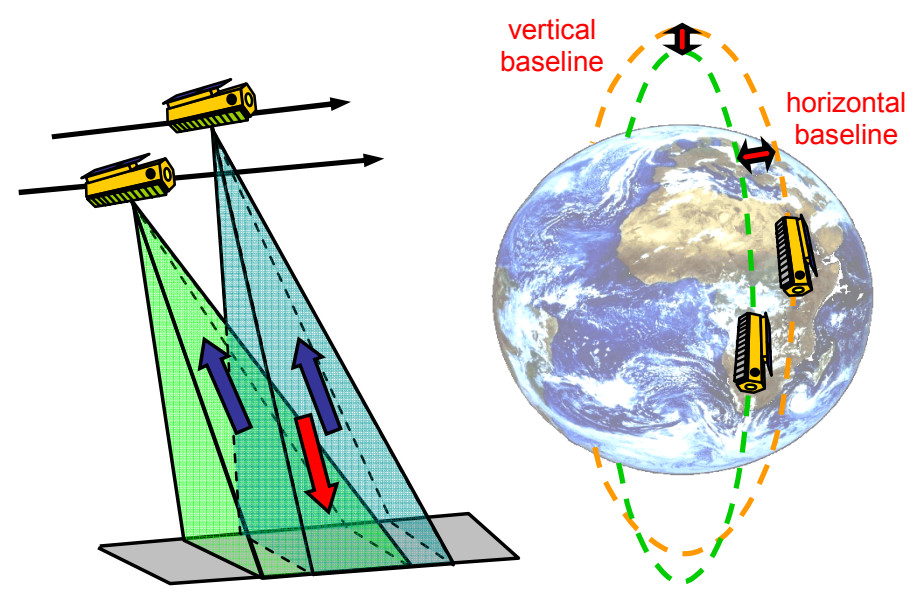

Figure 1. Bistatic InSAR Operation (left) and HELIX [7] orbit (right).

Interferometric data acquisition can be performed in (1) the pursuit monostatic mode where both satellites are operated independently, (2) the bistatic mode where one satellite serves as a transmitter and both satellites record the scattered signal simultaneously, and (3) the alternating bistatic mode where the transmitter changes from pulse to pulse. Current baseline for operational DEM generation is the bistatic mode which minimizes temporal decorrelation and makes efficient use of the transmit power. The alternating bistatic mode can be used for phase synchronization, system calibration, and to acquire interferograms with two different phase to height sensitivities, but the simultaneously acquired monostatic interferogram has a higher susceptibility to ambiguities especially at high incident angles [6]. Monostatic data takes are planned during the commissioning phase and at the end of the mission where the satellite formation is flown with a sufficient along-track separation between the satellites to avoid potential RF interferences.

The TanDEM-X operational scenario requires a coordinated operation of two satellites flying in close formation. Several options have been investigated and the HELIX satellite formation has finally been selected. This formation combines an out-of-plane orbital displacement (e.g. by different ascending nodes) with a radial (vertical) separation (e.g. by different eccentricity vectors) resulting in a helix like relative movement of the satellites along the orbit [7]. Since there exists no crossing of the satellite orbits, it is now possible to arbitrarily shift the satellites along their orbits, e.g. to adjust very small along-track baselines at predefined latitudes [8] and to allow safe spacecraft operation without autonomous control [9]. The HELIX formation enables a complete coverage of the Earth with a stable height of ambiguity by using a small number of formations (e.g. a. $\Delta \Omega=\{300 \mathrm{~m}, 400 \mathrm{~m}, 500 \mathrm{~m}\}$ and 
$\mathrm{a} \cdot \Delta \mathrm{e}=\{300 \mathrm{~m}, 500 \mathrm{~m}\},[10])$. Baseline fine tuning can be achieved by taking advantage of the natural rotation of the eccentricity vectors due to secular disturbances and fixating the eccentricity vectors at different relative phasings. An appropriate reference scenario has been derived which enables one complete coverage of the Earth with baselines corresponding to a height of ambiguity of ca. $35 \mathrm{~m}$ (see Sect. III) within somewhat more than 1 year assuming a bistatic acquisition in strip map mode with an average acquisition time of 140 s per orbit [10].

\section{PERFORMANCE ANALYSIS}

This section investigates the interferometric performance for TanDEM-X. For this, an interferometric data acquisition in bistatic strip map mode will be assumed. Table 1 summarizes the main instrument, orbit, and processing parameters which have been used in the performance analysis. Major factors which affect the relative height accuracy are the radiometric sensitivity of each SAR instrument, range and azimuth ambiguities, quantization noise, processing and co-registration errors as well as surface and volume decorrelation, scaled by the baseline length [11].

TABLE II. TANDEM-X SYSTEM PARAMETERS

\begin{tabular}{|c|c|c|c|}
\hline Parameter & Value & Parameter & Value \\
\hline Satellite Height (nom.) & $514 \mathrm{~km}$ & Antenna Length & $4,8 \mathrm{~m}$ \\
\hline Nominal Swath Width & $30 \mathrm{~km}$ & Antenna Width & $0,7 \mathrm{~m}$ \\
\hline Swath Overlap & $6 \mathrm{~km}$ & Antenna Elements & $32 \times 12$ \\
\hline Carrier Frequency & $9,65 \mathrm{GHz}$ & Antenna Tapering & linear phase \\
\hline Chirp Bandwidth & $<=150 \mathrm{MHz}$ & Antenna Mounting & $33.8^{\circ}$ \\
\hline Peak Tx Power & $2260 \mathrm{~W}$ & Quantization & 4 bits/sample \\
\hline Duty Cycle & $18 \%$ & Proc. Az. Bandwidth & $2266 \mathrm{~Hz}$ \\
\hline Noise Figure TRM & $4.3 \mathrm{~dB}$ & Misregistration & 0.1 pixel \\
\hline $\begin{array}{l}\text { Losses (proc., atm., } \\
\text { taper, degrad., ...) }\end{array}$ & $4.1 \mathrm{~dB}$ & $\begin{array}{l}\text { Sigma Nought Model } \\
\text { (Ulaby, } 90 \%, \text { X-band) }\end{array}$ & $\begin{array}{l}\text { Soil and } \\
\text { Rock, VV }\end{array}$ \\
\hline Indep. Post Spacing & $12 \mathrm{~m} \times 12 \mathrm{~m}$ & Along-Track Baseline & $<1 \mathrm{~km}$ \\
\hline
\end{tabular}

\section{A. Noise Equivalent Sigma Zero (NESZ)}

Figure 2 shows the predicted NESZ in strip map mode for the investigated $30 \mathrm{~km}$ swaths. The chirp bandwidth has been selected to yield a constant ground range resolution of $3 \mathrm{~m}$ and no antenna tapering was used to compensate for the steep sensitivity decay at the swath boarders. Future TanDEM-X system optimizations could include an appropriate Rx elevation tapering as well as a complete redefinition of the beams to improve both the sensitivity and the coverage by using optimized beams with less overlap. For reference, Figure 2 shows also the assumed scattering coefficients (cf. Table II) for occurrence levels of 50\% (dashed) and 90\% (dotted).

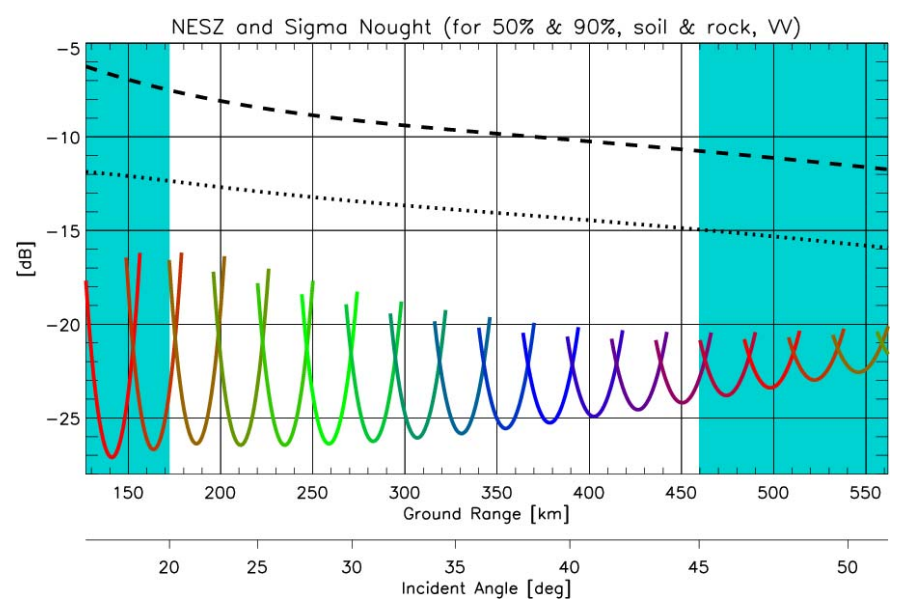

Figure 2. NESZ for untapered stripmap mode with $30 \mathrm{~km}$ swaths (solid) and scattering coefficients for $50 \%$ (dashed) and 90\% (dotted) occurrence levels.

\section{B. Total Coherence}

The total coherence has been computed by the product

$\tilde{\gamma}_{\text {tot }}=\gamma_{\text {SNR }} \cdot \gamma_{\text {Quant }} \cdot \gamma_{\text {Amb }} \cdot \gamma_{\text {Coreg }} \cdot \gamma_{\text {Geo }} \cdot \gamma_{A z} \cdot \widetilde{\gamma}_{\text {Vol }} \cdot \widetilde{\gamma}_{\text {Temp }}$

where the right hand side describes the different error contributions due to the limited SNR, quantization, ambiguities, limited coregistration accuracy, etc. (cf. [12]). The contribution from each of these terms has been evaluated for TanDEM-X and Figure 3 shows the predicted total coherence assuming the 50\% (dotted) and 90\% (solid) occurrence levels of the scattering coefficients.

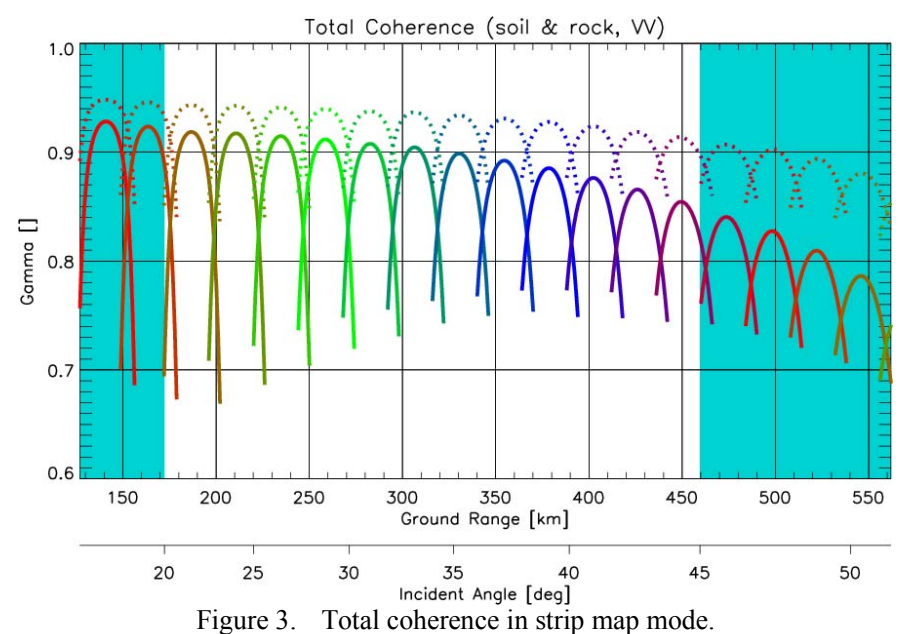

\section{Interferometric Phase Errors (Multilook)}

The interferometric phase errors have been estimated from the total coherence taking into account the number of independent looks obtained after spectral filtering in range and azimuth. Figure 4 shows the predicted interferometric phase errors for an independent post spacing of $12 \mathrm{~m} \times 12 \mathrm{~m}$. The phase error estimates have been obtained from a numerical evaluation of the multilook interferometric phase pdf by computing either the standard deviation for the $50 \%$ scattering coefficients (dotted) or by estimating the $90 \%$ occurrence interval in case of the $90 \%$ scattering coefficients (solid).

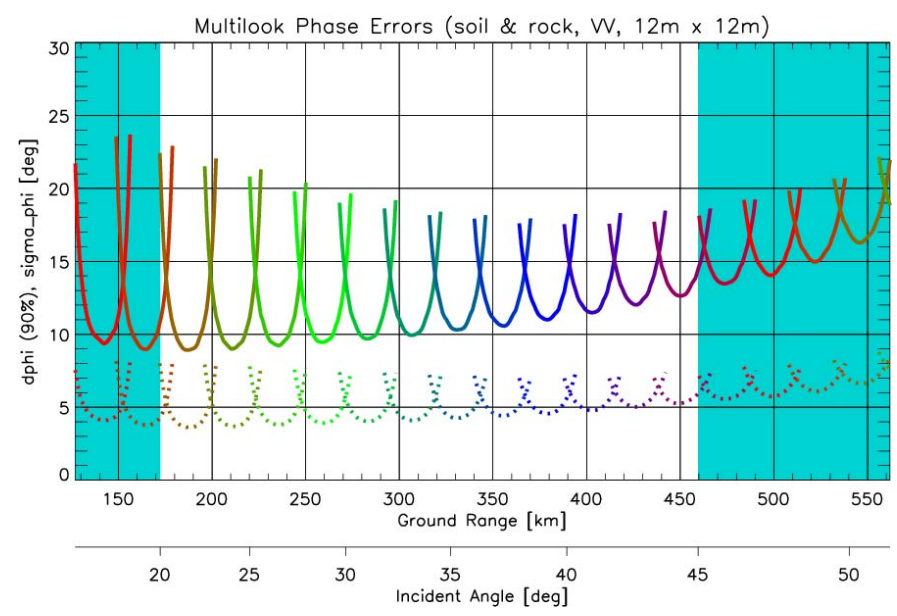

Figure 4. Interferometric phase errors for an independent post spacing of 12 m x 12 m. Solid: $90 \%$ confidence interval. Dotted: Standard deviation.

\section{Relative Height Accuracy}

Figure 5 shows the predicted height accuracy for an effective baseline of $600 \mathrm{~m}$ assuming an operation of TanDEM$\mathrm{X}$ in bistatic strip map mode. The solid lines indicate point-topoint height errors for a $90 \%$ confidence interval, and the dotted lines indicate the corresponding standard deviation. 


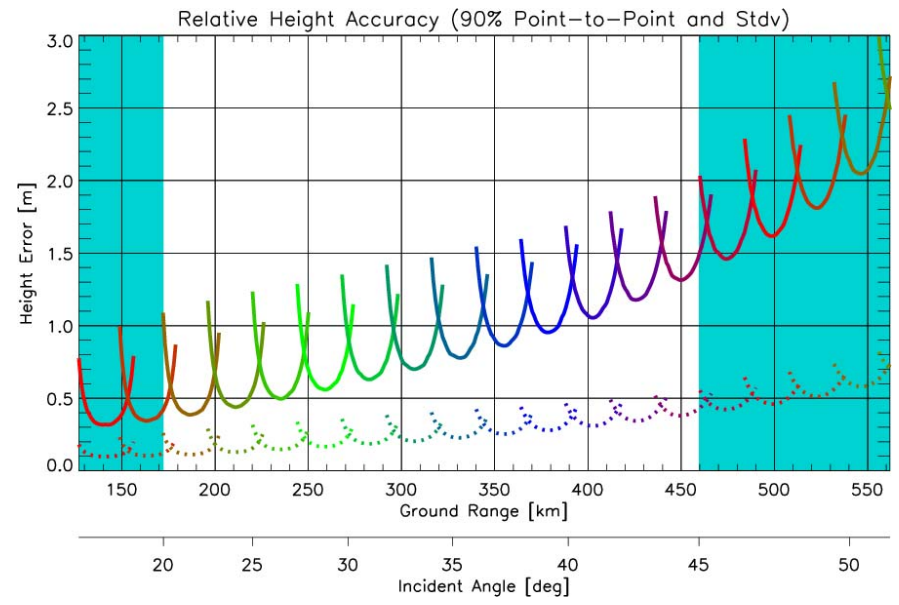

Figure 5. Relative height accuracy for an effective baseline of $600 \mathrm{~m}$ in strip map mode. (solid: point-to-point height errors for a $90 \%$ confidence interval., dotted: standard deviation)

The height errors in Figure 5 show a significant increase from near range to far range swaths. One reason for this increase is the systematic decrease of the phase to height scaling corresponding to a systematic increase of the height of ambiguity with increasing incident angles. As TanDEM-X enables a flexible selection of the interferometric baseline, it is hence advisable to adapt the length of the baselines to a fixed minimum height of ambiguity. As an example, Figure 6 shows the point-to-point height errors for the $90 \%$ confidence interval assuming fixed heights of ambiguity of $50 \mathrm{~m}$ (top), $35 \mathrm{~m}$ (middle), and 20m (bottom). Note that the derivation of the height accuracies assumes a maximum likelihood combination of the interferometric data from overlapping swath segments. The impacts of slopes, volume decorrelation, etc. have been analysed in [6], where it is shown that e.g. a variation of the slopes by $\pm 20 \%$ may cause a maximum increase of the height errors by a factor of $<1.1$ for medium incident angles and 1.2 for either very steep or very shallow incident angles.

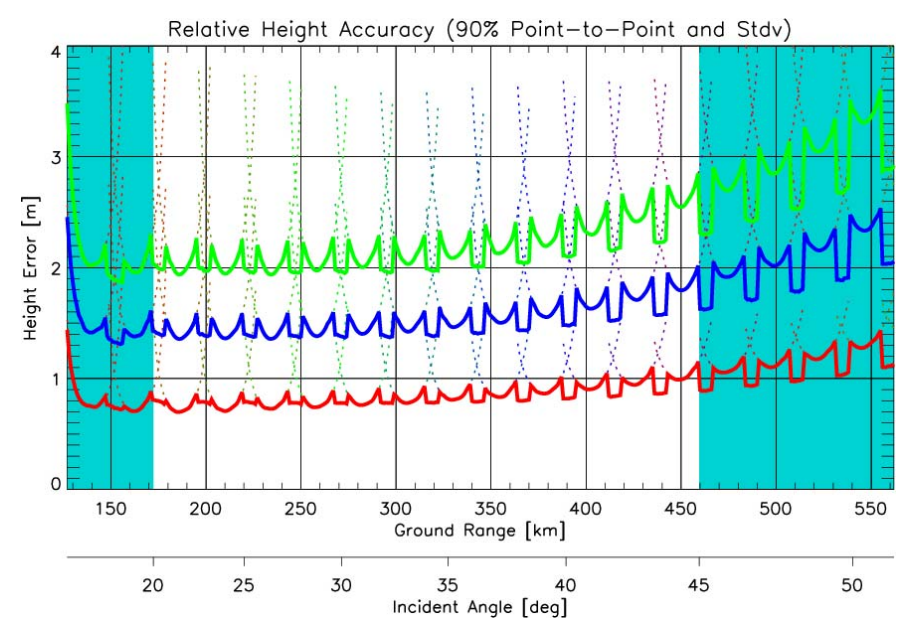

Figure 6. Height accuracy for fixed heights of ambiguity of $50 \mathrm{~m}$ (top, green), $35 \mathrm{~m}$ (middle, blue), and $20 \mathrm{~m}$ (bottom, red) in strip map mode after combination of adjacent swaths. All errors are point-to-point height errors for a $90 \%$ confidence interval.

It becomes apparent from Figure 6 that the acquisition of DEMs with $2 \mathrm{~m}$ relative height accuracy (point-to-point errors at $90 \%$ occurrence level according to HRTI-3 standard) will require a height of ambiguity which is in the order of $35 \mathrm{~m}$. This height of ambiguity corresponds to perpendicular baselines of $\mathrm{B}_{\perp}=260 \mathrm{~m}$ and $\mathrm{B}_{\perp}=439 \mathrm{~m}$ at incident angles of $30^{\circ}$ and $45^{\circ}$, respectively. It is clear, that unambiguous DEM generation in mountainous areas will require additional data acquisitions with different baselines to support phase unwrapping as described in [13], e.g., by employing an appropriate adaptation of the maximum likelihood technique suggested in [14]. The current TanDEM-X mission concept assumes 1-2 additional acquisitions for areas with moderate slopes and tall vegetation and 3-4 additional acquisitions for mountainous terrain with steep slopes. Phase unwrapping in forested areas may also be improved by evaluating the coherence loss due to volume decorrelation. Difficult terrain can furthermore be imaged with smaller baselines in the alternating bistatic mode, which enables the acquisition of two interferograms with an effective baseline ratio of two in one single pass.

\section{E. Baseline and Oscillator Errors}

Up to now, we have neglected errors due to the finite accuracy of relative baseline estimation and relative RF phase knowledge. Such errors will mainly cause a low frequency modulation of the DEM, thereby contributing simultaneously to relative and absolute height errors. For the latter, the HRTI-3 standard is much less stringent and requires an accuracy of only $10 \mathrm{~m}$ at a $90 \%$ confidence level.

Baseline estimation errors can be divided into along-track, cross-track, and radial errors. Along-track errors will be sufficiently resolved during the co-registration and are hence regarded as uncritical. Cross-track and radial errors may cause errors in both the line of sight $\left(\Delta \mathrm{B}_{||}\right)$and perpendicular $\left(\Delta \mathrm{B}_{\perp}\right)$ to the line of sight. Baseline errors perpendicular to the line of sight will cause a bias in the phase to height scaling. The resulting height error is given by $\Delta h=h * \Delta B_{\perp} / B_{\perp}$, where $h$ is the topographic height, $\Delta \mathrm{B}_{\perp}$ is the error of the baseline estimate perpendicular to the line of sight, and $B_{\perp}$ is the length of the perpendicular baseline. Assuming a maximum topographic height of $\mathrm{h}=9000 \mathrm{~m}$ and baselines corresponding to a height of ambiguity of $\mathrm{h}_{\mathrm{amb}}=35 \mathrm{~m}$ (i.e. $\mathrm{B}_{\perp}=260 \mathrm{~m}$ for $\theta_{\mathrm{i}}=30^{\circ}$ and $\mathrm{B}_{\perp}=439 \mathrm{~m}$ for $\theta_{\mathrm{i}}=45^{\circ}$ ), a baseline estimation error of $\Delta \mathrm{B}_{\perp}= \pm 1 \mathrm{~mm}$ will result in height errors of $\pm 3.5 \mathrm{~cm}$ and $\pm 2.1 \mathrm{~cm}$ for incident angles of $\theta_{\mathrm{i}}=30^{\circ}$ and $\theta_{\mathrm{i}}=45^{\circ}$, respectively.

Errors in the relative position estimates of the antenna phase centres parallel to the line of sight $\left(\Delta \mathrm{B}_{\|}\right)$will primarily cause a rotation of the reconstructed DEM about the (master) satellite position. As a result, the DEM will be vertically displaced by $\Delta \mathrm{h}=\Delta \mathrm{B}|| / \mathrm{B}_{\perp} * \mathrm{r} * \sin \left(\theta_{\mathrm{i}}\right)=\Delta \mathrm{B}|| \mathrm{h}_{\mathrm{amb}} / \lambda$ where $\mathrm{r}$ and $\theta_{\mathrm{i}}$ are the slant range distance and the incident angle of an appropriately selected reference point (e.g. at mid swath). This vertical displacement will be $\Delta \mathrm{h}= \pm 1.1 \mathrm{~m}$ for $\Delta \mathrm{B} \|= \pm 1 \mathrm{~mm}$ and $\mathrm{h}_{\mathrm{amb}}=35 \mathrm{~m}$. A parallel baseline error of one satellite will furthermore cause a tilt of the DEM which is given by $\varphi_{\text {tilt }}=\Delta \mathrm{h} / \Delta \mathrm{s}=\Delta \mathrm{B}_{||} / \mathrm{B}_{\perp}$ where $\Delta \mathrm{s}$ is the ground range distance from the selected reference point. The resulting tilt will be $3.8 \mathrm{~mm} / \mathrm{km}$ and $2.3 \mathrm{~mm} / \mathrm{km}$ for incident angles of $\theta_{\mathrm{i}}=30^{\circ}$ and $\theta_{\mathrm{i}}=45^{\circ}$, respectively $\left(\Delta \mathrm{B} \|=1 \mathrm{~mm}\right.$ and $\left.\mathrm{h}_{\mathrm{amb}}=35 \mathrm{~m}\right)$. Table 4 summarizes the predicted height errors resulting from $\Delta \mathrm{B}_{||}=1 \mathrm{~mm}$ and $\Delta \mathrm{B}_{\perp}=1 \mathrm{~mm}$.

TABLE III. HEIGHT ERRORS FOR 1MM BASELINE UNCERTAINTY

\begin{tabular}{|c|c|c|c|c|}
\hline \multirow{3}{*}{$\begin{array}{c}\text { Incident } \\
\text { Angle }\end{array}$} & \multirow{3}{*}{$\begin{array}{c}\text { Normal } \\
\text { Baseline } \\
\text { (hamb }=35 \mathrm{~m})\end{array}$} & \multicolumn{3}{|c|}{ Height Errors (for $h_{a m b}=35 m$ ) } \\
\hline & & \multicolumn{2}{|c|}{$\Delta \mathrm{B}_{\|}=1 \mathrm{~mm}$} & \multirow{2}{*}{$\begin{array}{l}\Delta \mathrm{B}_{\perp}=1 \mathrm{~mm} \\
\Delta \mathrm{h}(\mathrm{h}=9 \mathrm{~km})\end{array}$} \\
\hline & & $\Delta \mathrm{h}$ & $\Delta \mathrm{h} / \Delta \mathrm{s}$ (tilt) & \\
\hline $30^{\circ}$ & $260 \mathrm{~m}$ & \multirow{2}{*}{$1.1 \mathrm{~m}$} & $3.8 \mathrm{~mm} / \mathrm{km}$ & $3.5 \mathrm{~cm}$ \\
\hline $45^{\circ}$ & $439 \mathrm{~m}$ & & $2.3 \mathrm{~mm} / \mathrm{km}$ & $2.1 \mathrm{~cm}$ \\
\hline
\end{tabular}


The current mission concept assumes precise baseline determination by a direct evaluation of GPS carrier phase measurements. Current analyses indicate an achievable accuracy for the estimation of relative satellite positions in the order of 1-2mm [15]. The additional impact of satellite attitude errors and uncertainties in both the GPS and the RF antenna phase centre positions are currently being investigated. Note in this context that both satellites experience almost the same gravity field and are exposed to highly correlated orbit perturbations. Residual (i.e. unmodelled) variations of the baseline vector will hence show a high degree of temporal correlation. Even in case of a large differential acceleration of $\mathrm{a}=100 * 10^{-9} \mathrm{~m} / \mathrm{s}^{2}$ (e.g. due to unmodelled differential drag between the two satellites, etc.), the resulting differential error after a $100 \mathrm{~km}$ data take will be in the order of only $10 \mu \mathrm{m}$. Noting furthermore, that such an acceleration will mainly affect estimates of the along-track baseline (which are uncritical for cross-track interferometry), we may conclude that residual orbit fluctuations can be neglected in the computation of relative height errors (the area for relative point-to-point height errors in HRTI-3 is $100 \mathrm{~km} \times 100 \mathrm{~km})$.

Not neglected for the computation of relative height errors can, however, be the DEM tilt resulting from initial estimation errors of the relative RF antenna phase centre position. For example, an initial error in the estimate of the RF relative phase centre position of $\Delta \mathrm{B}_{\|}= \pm 1 \mathrm{~cm}$ can in the worst case result in a relative height error of $\pm 3.8 \mathrm{~m}$ for $\Delta \mathrm{s}=100 \mathrm{~km}$ (assuming an ideal mosaicking of equally tilted swaths). Such a tilt can be reduced by additional calibration data takes from crossing orbits by applying an appropriate bundle block adjustment in either radar or DEM geometry. Calibration data takes could also profit from larger baselines and/or different interferometric (e.g. pursuit monostatic or alternating bistatic) and/or different SAR (e.g. ScanSAR) modes. Absolute DEM calibration requires a final height accuracy of $10 \mathrm{~m}$ and will be based on a combination of (1) a sparse net of calibration targets, (2) GPS tracks, and (3) ocean data takes with short along-track baselines. Further calibration strategies are currently under investigation.

The impact of oscillator phase noise in bistatic mode has been analyzed in [16] where it is shown that oscillator noise may cause errors in both the interferometric phase and SAR focusing. Such errors can be estimated from a linear systems model that weights the power spectral density of the oscillator phase noise. The stringent requirements for interferometric phase stability in the bistatic mode will require an appropriate relative phase referencing or an operation in the ping-pong alternating bistatic mode. Direct transmission and reception of radar pulses is foreseen on both the TerraSAR-X and the TanDEM-X satellites. Assuming a height of ambiguity of $35 \mathrm{~m}$, the sensitivity to phase errors will be $h_{a m b} / 360^{\circ}=0.097 \mathrm{~m} / \mathrm{deg}$. The maximum allowed phase error for a height error of $\pm 1 \mathrm{~m}$ is hence $\pm 10.3^{\circ}$. The required update frequency in the direct transmission mode is in the order of $1-10 \mathrm{~Hz}$ depending on (1) the tolerable height errors, (2) the exact specification of the phase spectra of the two local oscillators, and (3) the phase noise on the 'synchronisation' link [16].

\section{CONCLUSION}

It has been shown that TanDEM-X allows for the derivation of highly accurate digital elevation models according to the emerging HRTI level 3 standard. The achievable height accuracy in TanDEM-X is mainly limited by the height of ambiguity that can finally be processed during phase unwrapping. A mission concept has been developed which enables the acquisition of a global DEM within three years. This concept includes several data takes with different baselines, different incident angles, and data takes from ascending and descending orbits to deal with difficult terrain like mountains, valleys, tall vegetation, etc.

The TanDEM-X mission concept allocates also sufficient acquisition time and satellite resources to secondary mission goals like moving target indication with a distributed four aperture displaced phase centre system, the measurement of ocean currents and the detection of ice drift by along-track interferometry, high resolution SAR imaging based on a baseline induced shift of the Doppler and range spectra (superresolution), the derivation of vegetation parameters with polarimetric SAR interferometry, large baseline bistatic SAR imaging for improved scene classification, demonstration of high resolution wide swath SAR imaging with four phase centre digital beamforming, as well as localized very high resolution DEM generation based on spotlight and/or large baseline interferometry [1][2].

Current work includes an optimization of the mission scenario by redefining the standard TerraSAR-X beams to improve both the performance and the coverage, an in depth analysis of the synchronization link, the development of a detailed calibration plan, the development of a multibaseline processing concept, as well as performance investigations for the other TanDEM-X imaging modes.

\section{REFERENCES}

[1] A. Moreira, G. Krieger, I. Hajnsek, M. Werner, D. Hounam, S. Riegger, E. Settelmeyer, TanDEM-X: A TerraSAR-X Add-On Satellite for Single-Pass SAR Interferometry, IGARSS 2004, Anchorage, USA.

[2] G. Krieger, A. Moreira, I. Hajnsek, D. Hounam, M. Werner, S. Riegger, E. Settelmeyer, A Tandem TerraSAR-X Configuration for Single-Pass SAR Interferometry, Radar 2004, Toulouse (see also ISPRS WS, 2005).

[3] I. Hajnsek, M. Weber, TanDEM-X: Science and Custom Exploration, IGARSS 2005, Seoul, Korea.

[4] R. Werninghaus, W. Balzer, St. Buckreuss, J. Mittermayer, P. Mühlbauer, The TerraSAR-X Mission, EUSAR 2004, Ulm, Germany.

[5] R. Hanssen, Radar Interferometry, Kluwer, Dordrecht, 2001.

[6] G. Krieger, TanDEM-X Phase A Study: Preliminary Mission Analysis and System Performance, TSXT-RD-DLR-1100, January 2005.

[7] A. Moreira, G. Krieger, J. Mittermayer, Satellite Configuration for Interferometric and/or Tomographic Remote Sensing by Means of Synthetic Aperture Radar (SAR), US Patent 6,677,884, July 2002. (see also Proc. Advanced SAR Workshop, Saint Hubert, Canada, 2001).

[8] H. Fiedler, G. Krieger, Close Formation of Passive Receiving Microsatellites, $18^{\text {th }}$ Int. Symp. Space Flight Dynamics, Germany, 2004.

[9] S. D'Amico, O. Montenbruck, C. Arbinger, H. Fiedler, Formation Flying Concept for Close Remote Sensing Satellites, AAS 05-156, 2005.

[10] H. Fiedler, TanDEM-X Phase A Study: Development of a Reference Scenario for TanDEM-X, April 2005.

[11] G. Krieger, H. Fiedler, J. Mittermayer, K. Papathanassiou, A. Moreira, Analysis of Multistatic Configurations for Spaceborne SAR Interferometry, IEE Proc. Radar, Sonar Navigation, Vol. 150, No. 3, pp. 87-96, 2003.

[12] G. Krieger, K. Papathannassiou, S. Cloude, Spaceborne Polarimetric SAR Interferometry: Performance Analysis and Mission Concepts, to appear in EURASIP Journal on Applied Signal Processing, 2005.

[13] M. Eineder, G. Krieger, Interferometric Digital levation Model Reconstruction - Experiences from SRTM and Multi Channel Approaches for Future Missions, IGARSS 2005, Seoul, Korea.

[14] M. Eineder, N. Adam, A maximum-likelihood estimator to simultaneously unwrap, geocode, and fuse SAR interferograms from different viewing geometries into one digital elevation model. IEEE Trans. Geosci. Remote Sens., Vol. 43, No. 1, pp. 24-36, 2005.

[15] R. Kroes, O. Montenbruck, W. Bertiger, P. Visser, Precise GRACE baseline determination using GPS, GPS Solut, Vol. 9, pp. 21-31, 2005.

[16] G. Krieger, A. Moreira, Spaceborne Bistatic and Multistatic SAR: Potentials and Challenges, to appear in IEE Proc. Radar Sonar Navigation, 2005. 